\title{
CORRECTION
}

\section{Correction to: A zero-waste approach to blast furnace slag by synthesis of mesoporous nanosilica with high surface area}

\author{
H. Fakhar ${ }^{1} \cdot$ J. Jiang ${ }^{2,3}$ \\ Published online: 17 September 2019 \\ (C) Islamic Azad University (IAU) 2019
}

\section{Correction to: International Journal of Environmental Science and Technology \\ https://doi.org/10.1007/s13762-019-02492-3}

The original version of this article unfortunately contained a mistake in Figure 1. The corrected Fig. 1 is given below.

The original article can be found online at https://doi.org/10.1007/ s13762-019-02492-3.

H. Fakhar

hooriya.fakhar@hotmail.com

1 School of Environment, Tsinghua University, Beijing 100084, China

2 Key Laboratory for Solid Waste Management and Environment Safety, Ministry of Education of China, Beijing 100084, China

3 Collaborative Innovation Center for Regional Environmental Quality, Tsinghua University, Beijing 100084, China 


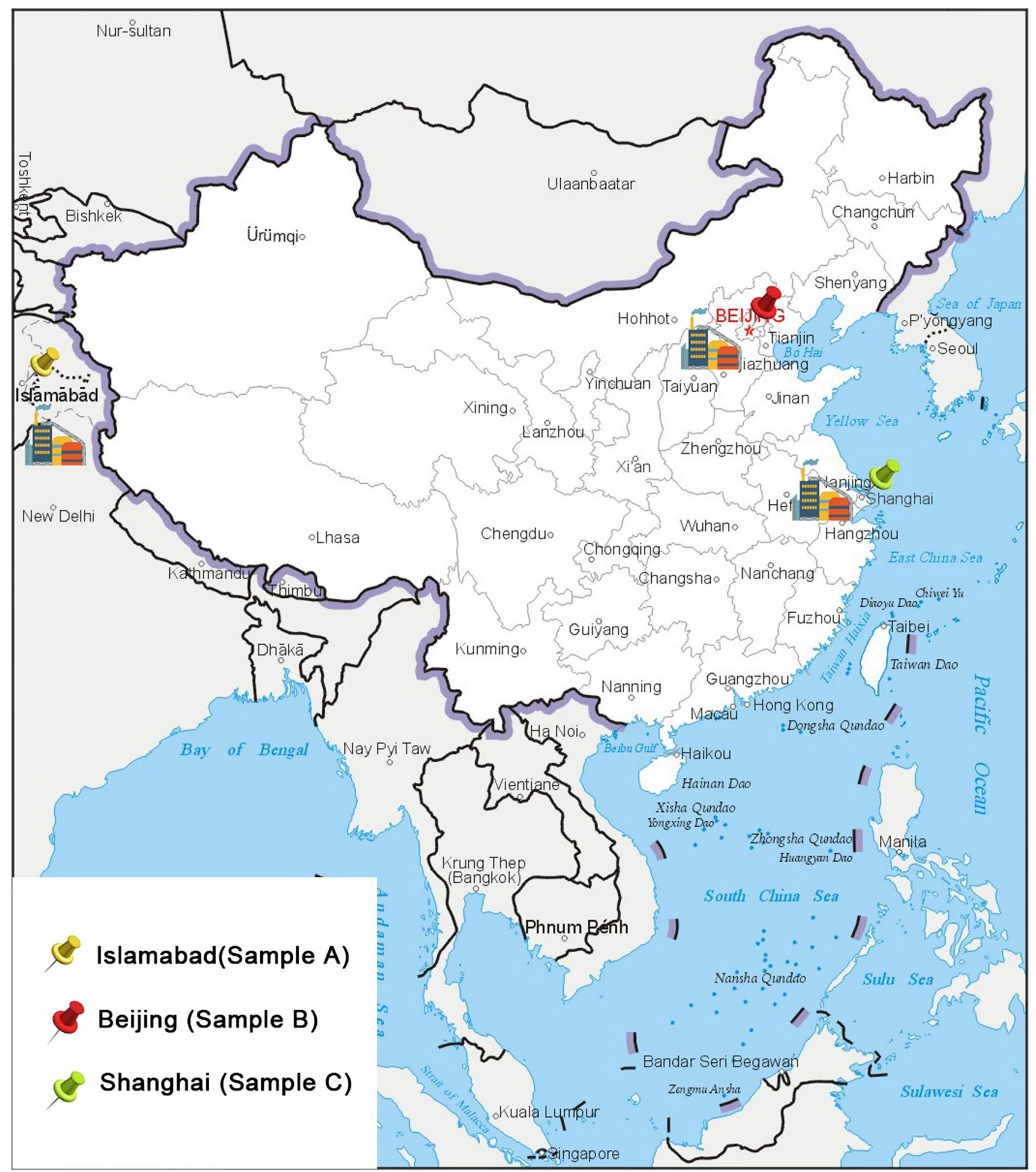

Fig. 1 Sampling sites 